\title{
Patient safety culture within a university hospital: feasibility trial
}

\author{
Gerald Sendlhofer $^{1,2^{*}}$, Christian Wölfler ${ }^{2}$ and Gudrun Pregartner ${ }^{3}$
}

\begin{abstract}
Background: Developing a patient safety culture is an evolving process for organizations. An accepted tool to assess the patient safety culture is the Hospital Survey on Patient Safety Culture (HSOPSC). Recently, the HSOPSC was translated into German. It was the primary aim of this short report to assess the reliability of the German HSOPSC within a university hospital in Austria.

Findings: The German version of the survey was adjusted to local circumstances. Finally, the survey contained 48 questions using the five-point Likert response scale of agreement. The online survey was sent out to 6317 employees. A total of 415 employees took part in the online survey (6.6\%). The majority ( $n=299,72.0 \%)$ had been employees without an executive function. 70 (16.9 \%) physician, 229 (55.2 \%) nurses, 47 (11.3\%) medical technical assistants and 69 (16.6 \%) administrative employees answered to the survey. The dimension that received the highest positive score was "manager expectations and actions promoting safety" (3.90 \pm 0.84 SD). Within outcome measures "patient safety in general" showed the lowest score ( $2.34 \pm 0.71 \mathrm{SD})$.

Conclusion: Reliability for the survey according to Cronbach's alpha coefficient was considered good. The German version of the HSOPSC can be a useful instrument within Austrian hospitals to assess the patient safety culture. This particular survey can be used as a reference value for further patient safety climate surveys within the organization.
\end{abstract}

Keywords: Patient safety, Patient safety culture

\section{Background}

Patient safety culture is determined by the requirement of understanding of values, attitudes, competences and patterns behavior and focus on organization's care processes and involved workforces [1-3]. However, developing a patient safety culture is an evolving process within an organization and needs patient safety programs on international, national and organizational levels. In 2006, the World Health Organization (WHO) launched the High $5 \mathrm{~s}$ project to address continuing major concerns about patient safety around the world [4]. For example, on a national level, the Austrian Federal Ministry of Health released a model for a distinct patient safety strategy and defined five intervention fields based on the

\footnotetext{
* Correspondence: gerald.sendlhofer@medunigraz.at

'Executive Department for Quality and Risk Management, University Hospital Graz, Graz, Styria, Austria

${ }^{2}$ Division of Plastic, Aesthetic and Reconstructive Surgery, Department of

Surgery, Medical University Graz, Graz, Styria, Austria

Full list of author information is available at the end of the article
}

capacity building concept and comprises i) policy development measures, ii) organization development, iii) personnel development measures, iv) monitoring measures and v) measures to raise public awareness [5]. Within the organizational level, clinical risk management and critical incident reporting systems accompanied with open communication and teamwork are some components to create a patient safety culture within an organization [6, 7].

Measuring patient safety culture can be performed in different ways such as interview-technique, on-site observations, focus groups and individual or self-administered questionnaires [3]. An accepted tool to assess the patient safety culture is the so-called Hospital Survey on Patient Safety Culture (HSOPSC) and was developed by the Agency for Healthcare Research and Quality [8]. The survey consists of 12 dimensions of culture pertaining safety. The HSOPSC is widely distributed in the USA and in the meantime also within Europe [3, 9-11]. Whereas in some 
European countries the assessment of the patient safety culture became mandatory and was linked to reimbursement as well as to issue reports on improvement strategies [10]. However, for Austria no such rules exist. HSOPSC survey results are available for organizations and investigated subgroups such as physicians, nurses, students or pharmacists' attitudes concerning patient safety [12-16].

In the past, questions about the applicability of the US HSOPSC arose [10] as significant differences between healthcare systems exist and suggest careful testing in other countries. Recently, the HSOPSC was translated into German and was tested within a University Hospital in Switzerland [11]. It was therefore the primary aim of this feasibility trial to assess if the German version of the HSOPSC is reliable within a university hospital in Austria. To the best of our knowledge this is the first report concerning the measurement of patient safety culture in Austria.

\section{Methods}

Questionnaire

ETH Zurich, Center for Organizational and Occupational Sciences [17] translated the HSOPSC survey into German. Survey results were separated into three levels:

- Level 1: 9 dimensions concerning the unit-level

- Level 2: 3 dimensions concerning the hospital-level

- Level 3: 4 Outcome measures

According to the recommendation of ETH the survey was changed to local circumstances. Within the dimensions "staffing" two questions were deleted and for "Manager expectations and actions promoting safety" one question was deleted. An additional file shows the final version of the survey as used in this feasibility trial [see Additional file 1].

Deleted questions were: 1) Staff in this unit work longer hours than is best for patient care; 2) We use more agency/temporary staff than is best for patient care; 3 ) Whenever pressure builds up, my supervisor/manager wants us to work faster, even if it means taking shortcuts. Furthermore, one outcome measure "number of event reporting" was not used within the feasibility trial, as the critical incident reporting system was implemented just in parallel and no valid results could have been expected. Finally, the survey contained 48 questions using the 5-point Likert response scale of agreement.

\section{Online survey}

In 2014, an online survey was conducted and was sent to 6317 employees. Email addresses were obtained from the in house mailing list. Employees were informed about the aim of the survey and were invited to participate. Furthermore, employees were informed that all data will be stored in the Department of Quality and
Risk Management and that data analysis will be strictly anonymous. Data tracking process and linking them to persons were explicitly excluded. Each participant was given a transaction authentication number (TAN) using the software Evasys, Healthcare Survey Automation Suite. Each TAN could only be used once and each person could only participate once. Employees had the free choice to decline participation or at any time to withdraw from the survey. Participants were given the possibility to skip questions if they felt uncomfortable with answering. The online survey was open for one month and after two weeks a reminder was sent from the system to non-responders. The conduct of the online survey was approved by the Medical University Graz Ethics Committee (vote-number: 26-172 ex 13/14).

\section{Statistical analysis}

Survey data were analyzed using descriptive statistics. Internal consistency of the questionnaire and its dimensions was measured by Cronbach's alpha coefficient. Reliability was considered good if values were $>0.7$ and very good if values were $>0.9$. All analyses were conducted using SPSS version 21 .

\section{Findings}

\section{Demographic statistics}

A total of 415 employees took part in the online survey (6.6 \%). The majority $(\mathrm{n}=299,72.0 \%)$ had been employees without an executive function. 70 (16.9 \%) physician, 229 (55.2 \%) nurses, 47 (11.3\%) medical technical assistants and 69 (16.6\%) administrative and other employees answered to the survey (Table 1). Employees from surgical departments had been the largest group

Table 1 Demographic data $(n=415)$

\begin{tabular}{lll}
\hline & & $\%$ \\
\hline Professional experience & $0-2$ years & 7.2 \\
& $2-5$ years & 12.3 \\
$5-10$ years & 19.3 \\
& $10-20$ years & 28.0 \\
& More than 20 years & 33.2 \\
Employment & Part time & 20.7 \\
Area of work & Full time & 79.3 \\
& Patient care & 93.2 \\
Professional group & Science & 4.1 \\
& Education & 2.7 \\
& Physician & 16.9 \\
& Nurse & 55.2 \\
& Medical Technical Assistant & 11.3 \\
& Administration and others & 16.6 \\
\hline
\end{tabular}


( $\mathrm{n}=191,46.0 \%$ ), followed by non-surgical departments $(\mathrm{n}=146 ; 35.2 \%)$, diagnostic departments $(\mathrm{n}=28,6.7 \%)$ and administration $(\mathrm{n}=50 ; 12.0 \%)$.

Concerning the 9 dimensions of level 1, "staffing" was ranked lowest whereas "Manager expectations and actions promoting safety" received the highest score (Table 2). Within level 2, all three dimensions were lower when compared to results affecting patient safety culture within a unit/department (level 1). The outcome measure "patient safety in general" was scored lowest within the survey. Comparing results for the subgroups of employees with and without managerial responsibility revealed that in general employees with managerial responsibility were more confident within nearly each dimension (Table 3). Overall, the reliability according to Cronbach's alpha coefficient for each question was good and ranged from 0.65 to 0.88 .

\section{Discussion}

In recent years it has been shown that the HSOPSC survey is a useful tool to assess the patient safety culture within healthcare environments. Since 2009, the University Hospital Graz initiated comprehensive patient safety initiatives $[6,18]$, however, employees perceived patient safety climate prior implementation of patient safety initiatives were not performed so far. In contrast to many European countries where the use of the HSOPSC became mandatory, the Austrian government did not recommend the survey so far. For that reason this feasibility trial represents the first institutional survey to assess the patient safety culture in an Austrian hospital.

The dimension that received the highest score was "manager expectations and actions promoting safety" and was even higher in the subgroup of employees with managerial responsibility. "Staffing" was expected to receive a low score and is comparable to already existing studies [2, 19]. All dimensions concerning hospital wide aspects were scored lower when compared to unit levels. Furthermore, employees with managerial responsibilities feel more positive than employees without managerial responsibilities.

The "overall perception of safety" was high whereas "patient safety in general" was scored low, in general and within the subgroups. On the one side, outcome measures reveal that more patient safety activities and information campaigns are needed. On the other side, participation in this feasibility trial was low, therefore results reflect trends.

In general a threshold for which patient safety can be considered as developed or has to improve would be helpful for future surveys [3]. Nevertheless, results give valuable hints for further improvements with respect to perceived patient safety culture. The key to success will be education and training of healthcare workers focusing on patient safety as well as greater awareness of patient safety amongst patients [20].

A limitation of the current study was the response rate to the online survey. Reason could be the fact that

Table 2 Pooled survey results $(n=415)$

\begin{tabular}{|c|c|c|c|c|c|}
\hline & Mean & $S D$ & Median & Min & $\operatorname{Max}$ \\
\hline \multicolumn{6}{|l|}{9 dimensions concerning a unit or department } \\
\hline Manager expectations and actions promoting safety & 3.90 & 0.84 & 4.00 & 1.00 & 5.00 \\
\hline Organizational learning & 3.78 & 0.69 & 4.00 & 1.33 & 5.00 \\
\hline Teamwork within hospital units & 3.58 & 0.71 & 3.50 & 1.25 & 5.00 \\
\hline Communication openness & 3.69 & 0.73 & 3.67 & 1.00 & 5.00 \\
\hline Feedback and error communication & 3.66 & 0.89 & 3.67 & 1.00 & 5.00 \\
\hline Non-punitive response to error & 3.36 & 0.88 & 3.33 & 1.00 & 5.00 \\
\hline Staffing & 2.88 & 0.93 & 3.00 & 1.00 & 5.00 \\
\hline Management support for patient safety & 3.64 & 0.80 & 3.75 & 1.00 & 5.00 \\
\hline Handoffs and transition within the unit & 3.59 & 0.76 & 3.75 & 1.00 & 5.00 \\
\hline \multicolumn{6}{|l|}{3 dimensions concerning the hospital } \\
\hline Teamwork across hospital units & 3.35 & 0.58 & 3.25 & 1.25 & 5.00 \\
\hline Handoffs and transition across units & 3.32 & 0.70 & 3.25 & 1.00 & 5.00 \\
\hline Supervisor expectations and actions promoting safety & 3.45 & 0.89 & 3.67 & 1.00 & 5.00 \\
\hline \multicolumn{6}{|l|}{3 Outcome measures } \\
\hline Frequency of event reporting & 3.45 & 1.11 & 3.67 & 1.00 & 5.00 \\
\hline Overall perceptions of safety & 3.68 & 0.73 & 3.75 & 1.00 & 5.00 \\
\hline Patient safety in general & 2.34 & 0.71 & 2.00 & 1.00 & 5.00 \\
\hline
\end{tabular}


Table 3 Comparing employees with a managing position (subgroup 1, $n=116$ ) to employees without managing position (subgroup 2, $n=299$ )

\begin{tabular}{|c|c|c|c|c|c|c|}
\hline & & Mean & SD & Median & Min & $\operatorname{Max}$ \\
\hline \multicolumn{7}{|l|}{9 dimensions concerning a unit or department } \\
\hline \multirow[t]{2}{*}{ Manager expectations and actions promoting safety } & Subgroup 1 & 4.13 & 0.79 & 4.00 & 1.00 & 5.00 \\
\hline & Subgroup 2 & 3.81 & 0.84 & 4.00 & 1.00 & 5.00 \\
\hline \multirow[t]{2}{*}{ Organizational learning } & Subgroup 1 & 3.88 & 0.71 & 4.00 & 1.67 & 5.00 \\
\hline & Subgroup 2 & 3.74 & 0.68 & 3.67 & 1.33 & 5.00 \\
\hline \multirow[t]{2}{*}{ Teamwork within hospital units } & Subgroup 1 & 3.78 & 0.70 & 3.75 & 1.75 & 5.00 \\
\hline & Subgroup 2 & 3.50 & 0.70 & 3.50 & 1.25 & 5.00 \\
\hline \multirow[t]{2}{*}{ Communication openness } & Subgroup 1 & 3.82 & 0.69 & 4.00 & 1.00 & 5.00 \\
\hline & Subgroup 2 & 3.64 & 0.75 & 3.67 & 1.00 & 5.00 \\
\hline \multirow[t]{2}{*}{ Feedback and error communication } & Subgroup 1 & 3.81 & 0.89 & 4.00 & 1.00 & 5.00 \\
\hline & Subgroup 2 & 3.61 & 0.89 & 3.67 & 1.00 & 5.00 \\
\hline \multirow[t]{2}{*}{ Non-punitive response to error } & Subgroup 1 & 3.55 & 0.85 & 3.67 & 1.00 & 5.00 \\
\hline & Subgroup 2 & 3.28 & 0.88 & 3.33 & 1.00 & 5.00 \\
\hline \multirow[t]{2}{*}{ Staffing } & Subgroup 1 & 2.99 & 0.94 & 3.00 & 1.00 & 5.00 \\
\hline & Subgroup 2 & 2.84 & 0.93 & 3.00 & 1.00 & 5.00 \\
\hline \multirow[t]{2}{*}{ Management support for patient safety } & Subgroup 1 & 3.79 & 0.80 & 4.00 & 1.00 & 3.79 \\
\hline & Subgroup 2 & 3.59 & 0.79 & 3.75 & 1.00 & 3.59 \\
\hline \multirow[t]{2}{*}{ Handoffs and transition within the unit } & Subgroup 1 & 3.56 & 0.81 & 3.50 & 1.00 & 5.00 \\
\hline & Subgroup 2 & 3.60 & 0.74 & 3.75 & 1.00 & 5.00 \\
\hline \multicolumn{7}{|l|}{3 dimensions concerning the hospital } \\
\hline \multirow[t]{2}{*}{ Teamwork across hospital units } & Subgroup 1 & 3.38 & 0.60 & 3.25 & 1.25 & 4.75 \\
\hline & Subgroup 2 & 3.34 & 0.57 & 3.25 & 1.75 & 5.00 \\
\hline \multirow[t]{2}{*}{ Handoffs and transition across units } & Subgroup 1 & 3.31 & 0.72 & 3.00 & 1.25 & 5.00 \\
\hline & Subgroup 2 & 3.33 & 0.69 & 3.25 & 1.00 & 5.00 \\
\hline \multirow[t]{2}{*}{ Supervisor expectations and actions promoting safety } & Subgroup 1 & 3.66 & 0.91 & 3.67 & 1.00 & 5.00 \\
\hline & Subgroup 2 & 3.37 & 0.87 & 3.33 & 1.00 & 5.00 \\
\hline \multicolumn{7}{|l|}{3 Outcome measures } \\
\hline \multirow[t]{2}{*}{ Frequency of event reporting } & Subgroup 1 & 3.60 & 1.04 & 4.00 & 1.00 & 5.00 \\
\hline & Subgroup 2 & 3.39 & 1.14 & 3.67 & 1.00 & 5.00 \\
\hline \multirow[t]{2}{*}{ Overall perceptions of safety } & Subgroup 1 & 3.76 & 0.74 & 3.75 & 1.00 & 5.00 \\
\hline & Subgroup 2 & 3.65 & 0.73 & 3.75 & 1.00 & 5.00 \\
\hline \multirow[t]{2}{*}{ Patient safety in general } & Subgroup 1 & 2.32 & 0.75 & 2.00 & 1.00 & 5.00 \\
\hline & Subgroup 2 & 2.35 & 0.69 & 2.00 & 1.00 & 5.00 \\
\hline
\end{tabular}

25-50\% of all employees within the hospital had no yet activated their email account [18]. Another reason can be the inflationary trend to perform surveys in general.

\section{Conclusion}

In conclusion, the German version of the HSOPSC was a useful instrument to investigate the patient safety culture, however, improvements are needed. To show a homogenous picture of a patient safety culture within the organization it is necessary to increase awareness and motivation to participate in further surveys. This survey can be used as a reference value for further patient safety climate surveys within the organization.

\section{Additional file}

Additional file 1: Final version of the online questionnaire.

Abbreviations

HSOPSC: Hospital Hospital Survey on Patient Safety Culture; WHO: World

Health Organization. 


\section{Competing interests}

The authors declare that they have no competing interests.

\section{Authors' contributions}

GS and CW designed the study. CW acquired the data. GP analyzed the data. GS drafted and finalized the manuscript. All authors have contributed with important intellectual content during manuscript revision and approved the final version of the manuscript.

\section{Acknowledgements}

The authors wish to express their gratitude to all employees who took part in this feasibility trial.

\section{Author details}

${ }^{1}$ Executive Department for Quality and Risk Management, University Hospital Graz, Graz, Styria, Austria. ${ }^{2}$ Division of Plastic, Aesthetic and Reconstructive Surgery, Department of Surgery, Medical University Graz, Graz, Styria, Austria. ${ }^{3}$ Institute for Medical Informatics, Statistics and Documentation, Medical University Graz, Graz, Austria.

Received: 10 April 2015 Accepted: 11 May 2015

Published online: 01 September 2015

\section{References}

1. Vlayen A, Hellings J, Barrado LG, Haelterman M, Peleman H, Schrooten W et al. Evolution of patient safety culture in Belgian acute, psychiatric and log-term care hospitals. Safety in Health 2015;1:2.

2. Chen I-C, Li HH. Measuring patient safety culture in Taiwan using the hospital Survey on Patient Safety Culture (HSOPSC). BMC Health Serv Res. 2010;10:152.

3. Occelli P, Quenon JL, Kret M, Domeca S, Delaperche F, Claverie O, et al. Validation of the French version of the Hospital Survey on Patient Safety Culture questionnaire. Int J Quality Healthcare. 2013;25:459-68.

4. World Health Organization, Action on Patient Safety - High 5s, http://www.who.int/patientsafety/implementation/solutions/high5s/en/ (accessed 14 May 2015)

5. Federal Ministry for Health. Nationwide Patient Safety Strategy for Austria 2013 - 2016. Vienna: Commissioned by the Federal Ministry of Health; 2013.

6. Sendlhofer G, Brunner G, Tax Ch, Falzberger G, Smolle J, Leitgeb K, et al. Systematic implementation of clinical risk management in a large university hospital: the impact of risk managers. Wien Klin Wochenschr 2015; doi: 10.1007/s00508-014-0620-7

7. Jardali F, Jaafar M, Dimassi H, Jamal D, Hamdan R. The current state of patient safety culture in Lebanese hospitals: a study at baseline. Int I Qual Health Care. 2010;22(5):386-95.

8. Agency of Healthcare Research and Quality http:/www.ahrq.gov/professionals/ quality-patient-safety/patientsafetyculture/ (accessed 14 May 2015)

9. Mikusova V, Rusnakova V, Nad'ova K, Boronova J, Bet'kova M. Patient safety assessment in Slovak hospitals. Int J Collab Res Int Med Public Health. 2012:4:1236-41.

10. Hedsköld M, Pukk-Härenstam K, Berg E, Lindh M, Soop M, Ovretveit J, et al. Psychometric properties of the hospital survey on patient safety culture, HSOPSC, applied on a large Swedish health care sample. BMC Health Services Res. 2013;13:332.

11. Van Vegten A, Pfeiffer Y, Giuliani F, Manser T. Patient safety culture in hospitals: experiences in planning, organizing and conducting a survey among hospital staff. Z Evid Fortbild Qual Gesundhwesen (ZEFQ). 2011;105:734-42.

12. Fujita S, Seto K, Kitazawa T, Matsumoto K, Hasegawa T. Characteristics of unit-level patient safety culture in hospitals in Japan: a cross-sectional study. BMC Health Serv Res 2014;14:508.

13. Richter JP, McAlearney AS, Pennell ML. The influence of organizational factors on patient safety: Examining successful handoffs in health care. Health Care Manage Rev Epub. 2014;1.

14. Armellino D, Quinn Griffin MT, Fitzpatrick JJ. Structural empowerment and patient safety culture among registered nurses working in adult critical care units. J Nurs Manage. 2010;18:796-803.

15. Bowman C, Neeman N, Sehgal NL. Enculturation of unsafe attitudes and behaviors: student perceptions of safety culture. Acad Med. 2013;88:1-9.
16. Patterson ME, Pace HA, Fincham JE. Associations between communication climate and the frequency of medical error reporting among pharmacists within an inpatient setting. J Patient Saf. 2013;9:129-33.

17. Manual zum Patientensicherheitsklima-Inventar (PaSKI). ETH Zürich, Center for Organizational and Occupational Sciences. http://www.beldonor.be/ internet2Prd/groups/public/@public/@dg1/@acutecare/documents/ ie2divers/19066312_de.pdf (accessed 14 May 2015)

18. Sendlhofer G, Mosbacher N, Leitgeb K, Kober B, Jantscher L, Berghold A, et al. Implementation of a surgical safety checklist: interventions to optimize the process and hints to increase compliance. PLoS ONE 10(2):e0116926. doi: 10.1371/journal.pone.0116926

19. Hellings J, Schrooten W, Klazinga N, Vleugels A. Challenging patient safety culture: survey results. Int J Health Care Quality Assurance. 2007;20(7):620-32.

20. Special Eurobarometer 327. Patient safety and quality of healthcare. European Commission http://ec.europa.eu/public_opinion/archives/ebs/ ebs_327_en.pdf (accessed 14 May 2015)

\section{Submit your next manuscript to BioMed Central and take full advantage of:}

- Convenient online submission

- Thorough peer review

- No space constraints or color figure charges

- Immediate publication on acceptance

- Inclusion in PubMed, CAS, Scopus and Google Scholar

- Research which is freely available for redistribution 